\title{
Within-field variability of wheat yield and economic implications for spatially- variable nutrient management
}

\author{
MJ Robertson ${ }^{A}$, G Lyle $^{B}$, JW Bowden ${ }^{C}$

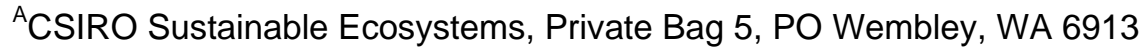 \\ B University of Adelaide, PMB1, Glen Osmond, SA, 5064 \\ ${ }^{\mathrm{C}}$ Department of Agriculture and Food WA, Centre for Cropping Systems, PO Box 483, Northam, WA \\ 6401
}

5

10

Corresponding author: Michael.Robertson@csiro.au

\begin{abstract}
Economic justification for varying fertiliser inputs to match crop yield potential of different areas or zones in fields is limited by lack of understanding of the relationship between the extent of within-field yield variation and economic gains from zone vs. uniform management. We conducted a survey of yield monitor data from 199 fields on the northern sandplain of the wheatbelt in Western Australia in order to document the extent of sub-field yield variation and test if variation is related to attributes such as yield and field area. The economic significance to zone management of the yield variation found in the survey along with variation in size of management zones, costs and prices, and soil fertility status was then assessed using a simple nutrient response model.
\end{abstract}

Considerable variation occurred in yield within fields. Standard deviation varied from 0.2 to $1.2 \mathrm{t} / \mathrm{ha}$ and the difference in yield between the highest and lowest yielding thirds of each field varied from 0.5 $\mathrm{t} / \mathrm{ha}$ in the least to $3.3 \mathrm{t} / \mathrm{ha}$ in the most variable field. Both small and large (10 to $172 \mathrm{ha}$ ), and low and high ( 0.6 to $4.9 \mathrm{t} / \mathrm{ha}$ ) yielding fields exhibited variation that was potentially worth managing from an economic standpoint. Model results showed that the larger the difference in potential yield between zones, the greater the economic benefit from zone management. While yield contrast within fields can be increased with more zones, the economic advantage of more zones was small for the cases studied here. The potential economic benefits (from $<\$ 5 / \mathrm{ha}$ to $\$ 44 / \mathrm{ha}$ ) increased with higher grain and fertiliser prices and depended on levels of soil nutrients in the different zones. Capturing the full value of the economic benefits in practice requires an accurate indication of yield potential in the different zones at the time when the fertiliser decision is being made. Yield maps can be utilised by growers to give estimates of within-field variation in yield potential and hence potential economic gains from variable rate application of fertiliser.

\section{Key words}

Precision agriculture, zone management, yield potential, economics, nutrient requirement, nitrogen, phosphorus, model. 


\section{Introduction}

A major concept behind the theory of precision agriculture (PA) is the matching of nutrient uptake to the spatial variability of grain yield over a farm. This form of precision management requires the use of advanced technologies such as global positioning and guidance systems, grain yield monitors and variable rate applicators. Emphasis on PA to date has been placed on the variable rate application of nutrients to different areas or zones in fields, hereafter called zone management (McBratney et al. 2005). Zone management is becoming more attractive due to the current cost-price squeeze in the Australian grains industry and the need for more efficient use of inputs such as fertiliser (Kingwell and Pannell 2005). The attractiveness of zone management to the grower is its numerous opportunities for increased profitability. In certain situations, the achievement of higher yields with higher input (Wong et al. 2001) can be achieved where the value of the extra yield outweighs the cost of the extra fertiliser. In other situations, increased profitability can be achieved through lower inputs where the cost savings exceed the reduced value of the yield either through the achievement of the same yield but with less fertiliser or a lower yield with less input.

Although the benefits of PA seem obvious, the adoption of spatially-variable fertiliser management is not widespread, both internationally (Daberkow and McBride 2003, Hudson and Hite 2001) and within Australia (Lowenberg-deBoer 2003). Although PA technology has been available in Australia for more than a decade, it has been estimated that only around $3 \%$ of Australian grain growers are using some form of the technology (Price 2004). One constraint to adoption is uncertainty in whether gross margin increases will exceed the costs of acquiring and operating PA technologies. Another uncertainty is whether enough within-field variation in yield exists to justify the investment (McBratney et al. 2005). Intuitively, one would expect that the economic and environmental benefits of zone management will be proportional to the extent of sub-field yield variation, where the biggest gains to be made will be in fields with the widest differences in yield potential (Godwin et al. 2003b, Pringle et al. 2003). This is because yield potential (defined here as the yield limited only by water) is the major determinant of crop nutritional requirements (Reid et al. 2002) and hence the greater the in-field variation in yield potential, the greater the opportunities exist for targeted application of fertiliser.

The aim of this paper is to examine the relationship between within-field yield variation and economic advantages for zone management, and the impact of variation in size of management zones, costs and prices, and soil fertility status. We report on the results of a survey of yield monitor data collected on the northern sandplain of the wheatbelt in Western Australia (WA) in order to document the extent of sub-field yield variation and test if variation is related to attributes such as field average yield and field area. The economic significance to zone management of the yield variation found in the survey is then assessed via a simple nutrient response model.

\section{Method}

Survey of within-field variability 
We conducted a survey of 199 wheat (Triticum aestivum L.) fields from the northern sandplain region ${ }^{3}$ of Western Australia (WA) (Table 1). The sandplain landscape of the northern wheat belt of Western Australia lies between $28.3^{\circ}$ and $30.7^{\circ} \mathrm{S}$ and $114.7^{\circ}$ and $116.8^{\circ} \mathrm{E}$, between the 300 and $400 \mathrm{~mm}$ mean annual rainfall isohyets. It currently produces some $15 \%$ of Australia's grain. It is a mixed cropping zone with cropping sequences based on spring wheat in rotation with grain lupins (Lupinus angustifolius) and sometimes pasture. The area is characterised by deep, well drained, yellow sandy loams and loamy sands. Annual rainfall in these areas is moderate to low, but the Mediterranean climate means that average winter rainfall is often in excess of evaporative demand.

Yield monitor data for each field were accessed from growers who have collaborated with CSIRO in 10 PA research from 1997 to 2002 near the locations of Buntine $\left(29.99^{\circ} \mathrm{S} 116.57^{\circ} \mathrm{E}\right)$, Three Springs $\left(29.53^{\circ} \mathrm{S} 115.76^{\circ} \mathrm{E}\right)$, Wongan Hills $\left(30.84^{\circ} \mathrm{S} 116.73^{\circ} \mathrm{E}\right)$ and Yuna $\left(28.33^{\circ} \mathrm{S} 114.96^{\circ} \mathrm{E}\right)$. A number of yield monitor datasets came from the same field over a few seasons. At Buntine, 9 fields were surveyed, 5 from 2 seasons and 4 from 1 season each. At Three Springs, 40 fields were surveyed, 1 over 5 seasons, 3 over 4 seasons, 8 over 3 seasons, 14 over 2 seasons and the remainder I season each. At Wongan Hills, 52 fields were surveyed, 3 over 3 seasons, 20 over 2 seasons and the remainder 1 season each. At Yuna, 15 fields were surveyed, 2 for 4 seasons, 1 for 3 seasons, 6 for two seasons and the remainder for 1 season each. In summary, 115 fields were surveyed with $70 \%$ of the total observations coming for 1 or 2 seasons per field. As such the survey was not random, however the assumption was that by analysing fields from a wide range of locations and seasons we could gain an overall picture of the extent of within-field yield variation for a large region of the WA wheatbelt.

\section{Processing of yield monitor data}

Management zones can be defined on the basis of patterns in yield variation, using clustering techniques where similar yielding areas are grouped into the same cluster or zone (Whelan and McBratney 2003). For the purposes of this study we clustered each of the 199 fields into 2, 3, 4 and 5 zones. The aim of this was to quantify the additional separation of yield variation gained by going from few to many zones within a field. Most analysis reported here concentrates on the 3-zone results.

Before clustering, the raw yield monitor data were extracted from different yield mapping software systems formats and passed through routines to provide a consistent data set for analysis. Positional data were transformed into the Geocentric Datum of Australia (GDA94) co-ordinate set and positional outliers caused by GPS error were removed. Estimates for grain yield (in t/ha) were then calculated with outlier values deleted above a specific physically improbable value for the region (>10 t/ha). Further, files were passed through a grain surge routine, which helped resolve yield surges from combine harvester dynamics based on a moving window of grain yield values (Beck et al. 1999; Robinson and Metternicht 2005).

Data were interpolated using kriging via the Vesper software (Whelan et al. 2001). These interpolated files, where each observation represented a $10 \mathrm{~m}^{2}$ area, were then imported into the SAS JMP statistical analysis software (SAS Institute Inc., 2003) for which k-means analysis was undertaken. 
The k-means analysis approach is a clustering method based upon a process of fitting data 4 iteratively to a specified number of clusters fixed a priori (defined here as 2 to 5 zones). This method creates disjoint zones using the EM algorithm by estimating cluster means, which maximise the Euclidean distance between the means and minimise the distances within the cluster groupings (Whelan and McBratney 2003). For each field, the total area and total mean yield were calculated as well as the total area and mean yield by cluster. An example of a yield map clustered into three zones is given in Figure 1.

Within-field yield variation was quantified in two simple ways: (1) the standard deviation of all yield estimates in the field, and (2) the range in mean yield from the highest yielding to the lowest yielding of the three zones (clusters) $\left(Y_{\text {diff }}\right)$. While this second measure has the effect of "hiding" variation within a zone by representing it as a zone mean yield, it is our experience that growers conceptualise withinfield variation in yield for management purposes as consisting of zones represented by a spatiallymeaned yield (Robertson et al. 2007). Correlations were then explored between both expressions of variation and field area and field mean yield.

Economic consequences of yield variation for zone management of nutrient inputs

A sensitivity analysis using a simple nutrient response model was conducted to determine the economic advantage of variable rate application over uniform (or blanket) field management of nitrogen $(N)$ and phosphate $(P)$ fertiliser, and hence the economic significance of the yield variation documented in the survey of yield monitored fields. Standard curves for response of wheat yield to $\mathrm{N}$ and $P$ were constructed, similar to those described by Colwell (1994). A similar approach is used in the NPDECIDE decision support package currently used for fertiliser application in Western Australia (Burgess et al. 1991).

In order to model the response of grain yield to $\mathrm{N}$ and $\mathrm{P}$ for any given situation, NPDECIDE starts with an estimate of potential grain yield. The potential yield is defined as the maximum yield that can be achieved by changing the levels of $\mathrm{N}$ and $\mathrm{P}$ available to the crop. Potential yield is used to account for all the factors which affect yield that are not dealt with specifically in the model. These can be site and soil type specific limitations, effect of season, or such factors as weeds, disease, or time of sowing. This is then scaled down by factors related to $\mathrm{N}$ and $\mathrm{P}$ nutrition to give an estimate of actual yield, according to the following formula:

$$
\mathrm{GY}=\mathrm{A}^{\star} \mathrm{P}_{\mathrm{sc}}{ }^{*} \mathrm{~N}_{\mathrm{sc}}
$$

Where GY is the estimated grain yield $(\mathrm{kg} / \mathrm{ha}), A$ is the potential grain yield $(\mathrm{kg} / \mathrm{ha}), \mathrm{P}_{\mathrm{sc}}$ is the $0-1 \mathrm{P}$ scalar, and $\mathrm{N}_{\mathrm{sc}}$ is the $0-1 \mathrm{~N}$ scalar.

On a given soil type, the yield limitation due to $\mathrm{P}$ nutrition depends on the amount of phosphate fertiliser added (the effect of form and placement of $P$ fertiliser are ignored here for simplicity), and the $P$ soil test level as follows:

$$
P_{s c}=\left(1-\exp \left(P_{f}^{*} C_{\text {fertp }}-C_{s t p}{ }^{*} P_{s t}\right)\right)
$$


where $P_{f}$ is the amount of fertiliser phosphorus added $(\mathrm{kg} / \mathrm{ha})$ and $P_{s t}$ is the phosphorus soil test value $(\mathrm{mg} / \mathrm{kg} 0-10 \mathrm{~cm}) . \mathrm{C}_{\text {fertp }}$ reflects the responsiveness of a particular soil type to added phosphorus and was set to 0.06 , and $\mathrm{C}_{\text {stp }}$ calibrates the value of the soil test level appropriately for that particular soil and was set to 0.12 .

5 The yield limitation due to $\mathrm{N}$ nutrition depends on the amount of $\mathrm{N}$ fertiliser added (as with $\mathrm{P}$ fertiliser, $\mathrm{N}$ form and placement effects are ignored), and the $\mathrm{N}$ soil test level as follows:

$$
\mathrm{N}_{\mathrm{sc}}=\left(1-\exp \left(\mathrm{N}_{\mathrm{f}}^{*} \mathrm{C}_{\text {fertn }}-\mathrm{C}_{\mathrm{stn}}{ }^{*} \mathrm{~N}_{\mathrm{st}}\right)\right)
$$

where $N_{f}$ is the amount of fertiliser $N$ added $(\mathrm{kg} / \mathrm{ha})$ and $N_{s t}$ is the $N$ soil test value $(\mathrm{kg} / \mathrm{ha}) . \mathrm{C}_{\text {fertn }}$ reflects the responsiveness of a particular soil type to added $\mathrm{N}$ and was set to 0.03 . $\mathrm{C}_{\mathrm{stn}}$, which calibrates the value of the soil test level appropriately for that particular soil, was set to 0.05 .

Response curves for $G Y$ versus $N_{f}$ and $P_{f}$ for a range of values for $A, N_{s t}, P_{s t}$ are given in Figure 2 .

A sensitivity analysis was undertaken to compare the uniform application of $\mathrm{N}$ and $\mathrm{P}$ fertiliser with its spatially-variable field equivalent with variable rate application of $\mathrm{N}$ and $\mathrm{P}$ to each zone. The fields were assumed to consist of three equal-sized zones, and the average yield potential for each zone varied in a range of scenarios so that relatively uniform fields were compared with highly variable ones (Table 2). In both uniform and variable situations, $\mathrm{N}$ and $\mathrm{P}$ rates were applied at their economicoptimum. In the uniform situation, the economically-optimum rates were calculated from the areaweighted values of the parameters from the field, whereas in the variable rate situation the rate for each zone was based upon its zone-specific parameters.

The economically-optimum rate was calculated at which gross return was maximised (in Australian dollars) using assumed costs for fertiliser and prices for wheat (Table 2). Optimum N and P fertiliser rates were then selected from a matrix where rates varied in increments of 10 and $5 \mathrm{~kg} / \mathrm{ha}$, respectively.

As starting soil fertility (parameters $N_{s t}$ and $P_{s t}$ in equations 2 and 3) will have an influence on the responsiveness of zones to variable rates of $N$ and $P$ these values were also varied (Table 2). Sensitivity tests were also conducted where the area proportion of the lowest or highest yielding zones were increased to occupy $70 \%$ of the field rather than $33 \%$ in the standard analysis (Table 2).

\section{Results}

Survey of within-field variability

Across the 199 fields, area ranged from 10 to 172 hectares (mean 72 hectares) and yield varied due to location and season from 0.5 to $4.9 \mathrm{t} / \mathrm{ha}$ (mean $2.4 \mathrm{t} / \mathrm{ha}$ ). There was no significant relationship between field size and average yield (results not shown).

Each field was zoned into 2, 3, 4 and 5 zones. The percentage of the field area in each zone was close to the expected for each zoning system, i.e. $50 \%$ for 2 zones, 33\% for 3 zones, $25 \%$ for 4 zones 
and $20 \%$ for 5 zones. For each zoning system there was variation in the size of the zones: for instance, with 3 zones more than 90\% of the fields had zones that varied between 25 and $40 \%$ of the field area.

With 2 zones, the median yields across the 199 fields in the 2 zones were 1.72 and $3.03 \mathrm{t} / \mathrm{ha}$ in 58 and $42 \%$ of the paddock, respectively (Table 3 ). The contrast between the lowest and highest yielding zones became greater with the larger number of zones used. With 3 zones the median yields of the lowest and highest yielding zones were 1.43 and $3.32 \mathrm{t} / \mathrm{ha}$, with 4 zones they were 1.24 and $3.47 \mathrm{t} / \mathrm{ha}$ and for 5 zones they were 1.12 and $3.61 \mathrm{t} / \mathrm{ha}$. Hence the difference between the lowest yielding zone and the highest yielding zone increased from $1.3 \mathrm{t} / \mathrm{ha}$ with 2 zones to $2.5 \mathrm{t} / \mathrm{ha}$ for 5 zones.

The following results pertain to only the 3 zone results. While it could be argued that larger fields might contain enough variation to justify the use of more than 3 zones and small fields enough variation to justify fewer zones, we have used a 3 zone system across the full range of field sizes as this is commonly the number of zones that growers use in variable rate application systems (Robertson et al. 2007). The two measures of within-field variability (standard deviation and $Y_{\text {diff }}$ ) were strongly correlated (Figure 3a). The intercept of the relationship was not significantly different from zero and the slope of 2.38 means that the value of $Y_{\text {diff }}$ is on average 2.4 times the standard deviation, e.g. a standard deviation of $0.7 \mathrm{t} / \mathrm{ha}$ corresponded to $a \mathrm{Y}_{\text {diff }}$ of $1.7 \mathrm{t} / \mathrm{ha}$. This relationship held over a range in standard deviation from 0.2 to $1.2 \mathrm{t} / \mathrm{ha}$ and $\mathrm{Y}_{\text {diff }}$ from 0.5 to $3.3 \mathrm{t} / \mathrm{ha}$. Standard deviation was not related to field mean yield, i.e. the coefficient of variation was not constant (Figure 3b), as also found by Godwin et al. (2003a).

The scatter plot of $Y_{\text {diff }}$ versus field area showed that, when using the 3 zone system, large fields were no more variable than small fields over a range of 10 to $172 \mathrm{ha}$, where $Y_{\text {diff }}$ varied from 0.5 to $3.2 \mathrm{t} / \mathrm{ha}$ (Figure 4a). A fitted regression to the relationship had a slope not significantly different from zero.

When expressed in terms in $Y_{\text {diff, }}$, high yielding fields were no more variable than low yielding fields over a range of 0.6 to 4.9 t/ha (Figure $4 \mathrm{~b}$ ). A fitted regression to the relationship had a slope not significantly different from zero. The full dataset contains yield monitor data collected from the same field over the seasons 1997-2002. It is possible that the lack of correlation between $\mathrm{Y}_{\text {diff }}$ and field mean yield was due to seasonal variability masking an underlying relationship. When the full dataset $(n=$ 199 ) is broken down to consider the correlation between field average yield and $Y_{\text {diff }}$ in each season,

30 then a similar result was obtained: i.e. a non-significant regression indicating no relationship between mean field yield and variability (data not shown).

There were strong relationships between the zone yields in a 3 zone system and the mean field yield (Figure 5). The mean field yield was equal to the yield of the middle yielding zone (Figure 5a) with the slope and intercept of the relationship not being significantly different from 1 and zero, respectively. The yield of the highest yielding zone was on average $0.6 \mathrm{t} /$ ha greater than that of the middle yielding zone (Figure $5 \mathrm{~b}$ ). Although the relationship between the yield of the middle yielding zone was strongly related to that in the low yielding zone, the $\mathrm{R}^{2}$ value was lower at 0.75 and the slope and intercept were significantly different from 1 and zero, respectively (Figure 5c). The existence of these relationships suggests that knowledge of the field average yield can be used to predict a priori the 
yield of the middle and highest yielding zones and, to a lesser extent, the lowest yielding zone. Individual field circumstances will vary around these generalisations, but they provide an insight into broad trends that can be used to asses the likelihood of significant yield variation for a region.

\section{Economic significance of variation in potential yield}

The economic significance of the variation in yield observed in the survey of yield monitored fields was assessed by comparing variable application of $\mathrm{N}$ and $\mathrm{P}$ in a 3 zone system against uniform application to the field (Figure 6, Tables 4 and 5).

The economic advantage of zone management over uniform management can be expressed as a continuous function of the yield difference between the lowest and highest yielding zones in a field, where the middle zone is equal to the mean of the low and high zones. Figure 6 shows, for the case where the low zone is $0.5 \mathrm{t} / \mathrm{ha}$, the advantage of variable rate application of $\mathrm{N}$ ranges from negligible levels at $Y_{\text {diff }}$ of $0.5 \mathrm{t} / \mathrm{ha}$ up to $\$ 15 / \mathrm{ha}$ for $Y_{\text {diff }}$ of $3.5 \mathrm{t} / \mathrm{ha}$. This range spans the range of variation found in the yield monitor survey.

Three sets of yield variation across zones, spanning the range found in the yield monitor survey, are now used to illustrate the impact of yield variation in combination with other factors (see Table 2 for other assumed values). Field mean yield is the same in all cases (1.75 t/ha) with low inter-zone variation being 1.5, 1.75 and 2.0 t/ha, standard at 1.0. 1.75 and $2.5 \mathrm{t} / \mathrm{ha}$, and high inter-zone variation at $0.5,1.75$ and $3.0 \mathrm{t} / \mathrm{ha}$. For the standard case, the optimum $\mathrm{N}$ rates for the three zones will be 0,20 and $40 \mathrm{kgN} / \mathrm{ha}$ against the field optimum of $20 \mathrm{kgN} / \mathrm{ha}$ giving an advantage to zone management of $\$ 2 /$ ha (see scenario 1 in Table 4). If yield variation increases to $0.5,1.75$ and 3.0 t/ha then the advantage increases to $\$ 7 / \mathrm{ha}$, while if the yield variation decreases to $1.5,1.75$ and $2.0 \mathrm{t} / \mathrm{ha}$ the advantage drops to $\$ 0 / \mathrm{ha}$. In all three cases of yield variation the advantage to zone management comes from higher rates of fertiliser $\mathrm{N}$ applied to the medium and high zones compared to the uniform field rate of $20 \mathrm{kgN} / \mathrm{ha}$. In addition, in the case of high yield variation, a benefit accrues from cost savings on the low yielding zone with less fertiliser $\mathrm{N}$ applied than the uniform field rate.

If $\mathrm{P}$ responses are now considered (scenario 2 in Table 4), the advantage to zone management increases from the $\mathrm{N}$-only situation (scenario 1 ) of $\$ 1-7 /$ ha to $\$ 0-8 /$ ha. Again, this is due to optimum $P$ rates in the high yield zone being $5-10 \mathrm{kgP} / \mathrm{ha}$ compared to the uniform field rate of $0 \mathrm{kgP} / \mathrm{ha}$.

The additional impact of zonal differences in soil fertility status is assessed in Scenario 3 in Table 4 with the occurrence of low $\mathrm{N}$ and $\mathrm{P}$ status on the high yielding zone and high $\mathrm{N}$ and $\mathrm{P}$ status on the low yielding zone. This situation could be envisaged as a field with a history of uniform fertiliser application that has resulted in accumulation of nutrients in the low yielding zone and decline of nutrient levels in the high yielding zone. Benefits for zone management for $N$ and $P$ vary from $\$ 21$ to $\$ 44 /$ ha for low to high yield variation cases. Much larger benefits occur in this scenario than in scenarios 1 and 2 because there is much yield foregone in the high yielding zone by not accounting for its lower $\mathrm{N}$ and $\mathrm{P}$ status and higher yield potential compared to the field when managed uniformly. For example, uniform field optimum rates of $\mathrm{N}(10-40 \mathrm{kgN} / \mathrm{ha})$ and $\mathrm{P}(10-20 \mathrm{kgP} / \mathrm{ha})$ are considerably less that the optima for the high yielding zone of $60 \mathrm{kgN} / \mathrm{ha}$ and $30-40 \mathrm{kgP} / \mathrm{ha}$. In addition, there are 
cost savings in the low and medium zones because of the higher fertility status of $\mathrm{N}$ and $\mathrm{P}$ producing zone optima of $0 \mathrm{kgP}$ and $0 \mathrm{kgN} / \mathrm{ha}$ that are considerably less than the uniform field rates.

In the reverse case (scenario 4 in Table 4) where the occurrence of high $\mathrm{N}$ and $\mathrm{P}$ status on the high yielding zone and low $\mathrm{N}$ and $\mathrm{P}$ status on the low yielding zone the benefits are less than in scenario 3

5 (\$1-20/ha). This is because in the case of uniform management the high zone is fertilised close to the zone optimum and hence the benefits from zone management are not as great. This situation could be envisaged as occurring where previous $\mathrm{N}$ contributing crops (e.g. crop legumes or pasture) leave more residual $\mathrm{N}$ on high yielding zones and less on low yielding zones.

The analysis considered to this point assumes three zones of equal size in a field. Two scenarios, where the low and high zones dominate the field at $70 \%$ of the area, are compared with the base case of equal sized zones for $\mathrm{N}$ and $\mathrm{P}$ management (Table 5). With equal-sized zones benefits for zone management vary from $\$ 0$ to $\$ 8 / \mathrm{ha}$. Where the low zone dominates the field (scenario 2 ) benefits to zone management are greater ( $\$ 2-5 / \mathrm{ha})$ than if the high yielding zone dominates (scenario 3 ) (\$06/ha). In all three scenarios the zone optima for $N$ and $P$ are the same - the benefits to zone management occur due to the degree to which the uniform field rate, calculated from the areaweighted zone attributes, matches the zone optima. The scenario of the low zone dominating the field gives greatest advantages to zone management, because the uniform field rate is less than the optima for the high zone and this is where yield is lost under uniform management due to under-fertilisation.

With standard settings for yield variation, $N$ and $P$ soil fertility status and zone sizes (Table 2) the impact of variation in $\mathrm{N}$ fertiliser cost and grain price on the advantage to zone management was assessed. The advantage varied from \$4-10/ha and was most clearly affected by a fall in grain price (Figure 7). There was a smaller impact of increase in grain price and changes in $\mathrm{N}$ fertiliser cost.

\section{Discussion}

\section{Within-field yield variation}

The survey of 199 wheat fields monitored for yield from the northern sandplain of the WA wheatbelt provides us with an estimate of the likely range of within-field variation in grain yield, from a data set where fields ranged up to 172 ha in area and 4.9 t/ha in average yield. When variability is expressed in terms of the difference in zone mean yield of the highest and lowest thirds of a three zone system $\left(Y_{\text {diff }}\right)$, it ranged from $0.5 \mathrm{t} / \mathrm{ha}$ in the most uniform field up to $3.2 \mathrm{t} / \mathrm{ha}$ in the most variable field. The fact that $Y_{\text {diff }}$ was on average 2.4 times the field standard deviation means that if one expression is known then the other can be predicted with some certainty. This will be helpful when converting between a statistical description of variation (standard deviation) and one that has more agronomic meaning ( $\mathrm{Y}_{\text {diff }}$. The standard deviation of yield varied from 0.2 to $1.2 \mathrm{t} / \mathrm{ha}$, with a mean of $0.7 \mathrm{t} / \mathrm{ha}$. This is comparable to the range of 0.24 to 1.45 (mean $=0.69$ ) t/ha given by Pringle et al. $(2003$ ) for 11 wheat crops from northern New South Wales and central WA that varied in yield from 0.96 to $5.6 \mathrm{t} / \mathrm{ha}$. This suggests that the variation seen in our survey is representative of variation seen in broadacre Australian agriculture. Similar levels of variation have been noted in higher yielding situations. In the 
study of Blackmore et al. (2003) of wheat crops in the UK that varied from 4.2 to 9.5 t/ha, the spatial standard deviation was unrelated to the field mean and varied from 0.7 to $2 \mathrm{t} / \mathrm{ha}$.

When using the three zone system, $\mathrm{Y}_{\text {diff }}$ was unrelated to field size or field yield. This suggests that opportunities for exploiting variation for variable nutrient management occur in both small and large

5 fields, and in low and high yielding situations. While it could be argued that this result is a consequence of the three zone system "hiding" significant within-zone variation as field size increased, this was not supported by the lack of relationship between field standard deviation and field size or field mean yield. Regardless of these points, in our experience, growers commonly use 3 zones when implementing variable rate application systems irrespective of field size. When implementing such a system it is clear that smaller fields are no lesser candidates for zone management than larger fields.

There was also no relationship between field mean yield and $Y_{\text {diff. }}$. Fields with yields as low as $0.8 \mathrm{t} / \mathrm{ha}$ and as high as 3.5 t/ha had a yield range that varied between 1 and 3 t/ha. This suggests that opportunities for zone management exist in comparatively low as well as high-yielding situations, and also that high yielding fields do not automatically contain enough yield variation worth managing.

The yield of the middle yielding zone was found to be approximately equal to the mean field yield, and also predicted the yield of the high yielding zone, and to a lesser extent the yield of the low yielding zone. While individual field circumstances will vary, these broad relationships derived across the 199 yield maps means that for a given mean field yield expectation the yields in the middle and high zones could be predicted. The yields in the low yielding zone will be less predictable.

The question of whether there are economic gains to be made in considering more or less than 3 zones, can be answered by examining the yield contrast gained in 2, 3, 4 or 5 zones. Although the analysis in this paper considered the case of fields with three management zones, it is interesting to assess the scope for further partitioning of yield variation with greater numbers of zones, especially if this were feasible on larger fields. A suggested move from two to five zones causes the mean difference between the lowest and highest yielding zones to increase from $1.3 \mathrm{t} / \mathrm{ha}$ to $2.5 \mathrm{t} / \mathrm{ha}$. With more zones the potential larger economic gains through greater partitioning of yield variation are occurring on a smaller proportion of the field. By definition, economic advantages will increase with more zones. For the simple case here, considering the median yields in a 2, 3, 4 or 5 zone system found in the survey (Table 3), the economic advantages range from $\$ 3 /$ ha for a 2 zone system up to $\$ 4 /$ ha for 5 zones. This suggests that for the cases of within-field variability described here there are diminishing returns in moving to more zones in an attempt to extract greater gains from targeting fertiliser to yield potential. There is also greater demand on management time and analysis.

\section{Economic significance of variation in potential yield}

The economic sensitivity analysis provides the full range of advantages that are possible with zone management compared to uniform management. For the assumptions presented in this study, the economic benefits to WA growers ranged from $<\$ 5 / \mathrm{ha}$ to over $\$ 40 / \mathrm{ha}$, and are similar to the benefits derived by Brennan et al. (2006) in northern New South Wales and Godwin et al. (2003a) in the United Kingdom. At current typical gross margins at $\$ 100 /$ ha for this region of WA for yields of $1.7 \mathrm{t} / \mathrm{ha}$ 
(Department of Agriculture and Food Western Australia 2005), advantages to zone management of 10 as little as $\$ 10 /$ ha represent a sizable increase on a baseline gross margin.

The advantages gained through zone management were seen mostly via higher rates of fertiliser on medium and high yielding zones, and to a lesser extent as lower rates, and thus cost savings, on low yielding zones. The analysis here allowed the total amount of fertiliser applied to the field to vary from the uniform rate with the zone management scenarios. For example, in most scenarios considered in Tables 4 and 5 the amount of fertiliser applied to the field was greater than that applied in the uniform situation. In many grower situations, the amount of fertiliser that can be applied is constrained financially and moving to a zone management system the objective is not to increase the total amount applied but simply target nutrient application differently within the field. Further analyses, outside the scope of this paper, should assess the degree to which the advantages to zone management documented here are diminished under the situation of a constrained fertiliser budget.

The analysis has confirmed the overriding importance of variation in yield potential in determining potential advantages to zone management, as also found by Adams et al. (2000). The within-field variation in the survey between the lowest and highest yielding thirds of the field ranged from $0.5 \mathrm{t} / \mathrm{ha}$ in the most uniform fields to 3.5 t/ha in the most variable. These differences correspond to advantages to zone management of around $\$ 1 /$ ha to about $\$ 15 /$ ha. The median difference in the survey was 1.7 t/ha and this would correspond to an advantage to zone management for $\mathrm{N}$ on wheat of $\$ 4 /$ ha.

20 The sensitivity analysis showed that if zone differences in starting soil fertility co-occur with differences in yield potential then this will add considerably to the benefits of zone management if they can be accounted for in fertiliser rates. When moving from scenario 2 (uniform fertility across zones) to 3 (high starting fertility in low yielding zones) in Table 4 the benefits to zone management increase for $\$ 0-8 /$ ha to $\$ 21-44 / h$. The gains are less when moving to a situation where there is high starting fertility on the high yielding zones (\$1-20/ha). This is because in the case of uniform management, the high zone is fertilised close to the zone optimum and hence the benefits from zone management are not as great. The important point to take from this result is that knowledge of variation in soil fertility can be estimated prior to the fertiliser application via soil sampling. This is in contrast to the prediction of yield potential, which is nearly always unknown at the time of the fertiliser decision being made.

A qualification to the economic benefits described above to zone management is that they depend on fertiliser being able to be matched to yield potential. Whelan and McBratney (2000), after demonstrating that temporal variability in Australian grain crops was larger in magnitude than spatial variability, concluded that the risk of economically inappropriate management will be increased if spatially-variable management options are based on analyses that fail to incorporate the effects of temporal variability. They also noted that in the published literature on PA, most economic comparisons of spatial and uniform management neglected the impact of temporal variability.

Even with in-season applications of fertiliser to match evolving seasonal conditions there is residual uncertainty in the yield outcome. Further advances in quantifying the benefits of zone management will require linking knowledge of spatial variability with systems for seasonal climate forecasting (Brennan et al. 2006, Hayman 2001). 
Additional effects on the economic advantages to zone management were the relative size of the low yielding zone (Table 5), and costs of fertiliser and prices for grain (Figure 7). These were less significant than effects of variation in yield potential and starting soil fertility.

\section{Conclusions}

5 Considerable variation occurs in potential yield within fields in our study area. Both small and large, and low and high yielding fields exhibited variation that was potentially worth managing from an economic standpoint. The larger the difference in potential yield between zones the more economic benefit from zone management. While yield contrast within fields can be increased with more zones, the economic advantage of more zones was small for the cases studied here. The economic benefits increased with higher grain and fertiliser prices and depend on levels of soil nutrients in the different zones. Capturing the full value of the economic benefits in practice requires an accurate indication of yield potential in the different zones at the time when the fertiliser decision is being made. Yield maps can be utilised by growers by giving estimates of within-field variation in yield potential and hence economic gains from variable rate application of fertiliser.

\section{Acknowledgments}

The authors would like to thank lan Maling, Matt Adams, Mike Wong, Yvette Oliver, Bob Belford and Phil Price for providing stimulating discussions that have influenced the ideas in this paper. This work has been funded through the Grains Research and Development Corporation program on precision agriculture.

\section{References}

Adams ML, Cook S, Bowden JW (2000) Using yield maps and intensive soil sampling to improve nitrogen fertilizer recommendations from a deterministic model in the Western Australian wheatbelt. Australian Journal of Experimental Agriculture 40, 959-968.

Beck, AD, Roades JP, Searcy SW (1999) Post-process filtering techniques to improve yield map accuracy. In: 1999 ASAE/CSAE-SCGR Annual International Meeting, Sheraton Toronto, Toronto, Ont., Canada, July 18-21, 1999.

Blackmore S, Godwin RJ, Fountas S (2003) An analysis of spatial and temporal trends in yield map data over six years. Biosystems Engineering 84, 455-466.

Brennan LE, Robertson MJ, Dalgliesh NP, Brown S (2006) Pay-offs to zone management of fertiliser in a variable climate: a study of nitrogen fertiliser on wheat. Australian Journal of Agricultural Research.(in review)

Burgess SJ, Bowden JW, Diggle AJ (1991) NPDecide User's guide: A computer program to help with nitrogen and phosphorus fertiliser decisions for cereals. Department of Agriculture, Western Australia.

Colwell JD (1994) Estimating fertilizer requirements: A quantitative approach. CAB International, Wallingford, UK, $262 \mathrm{pp}$. 
Cook SE, Bramley RGV (1998) Precision agriculture - opportunities, benefits and pitfalls of sitespecific crop management in Australia. Australian Journal of Experimental Agriculture 38, 753763.

Department of Agriculture and Food Western Australia (2005) Gross Margin Guide for the Northern Agricultural region. Accessed at www.agric.wa.gov.au on $20^{\text {th }}$ April 2006.

Daberkow SG, McBride WD (2003) Farm and operator characteristics affecting the awareness and adoption of precision agriculture technologies in the US. Precision Agriculture 4, 163-177.

Fairfield Smith $\mathrm{H}$ (1938) An empirical law describing heterogeneity in the yields of agricultural crops. Journal of Agricultural Science, Cambridge 28, 1-23.

Godwin RJ, Richards TE, Wood GA, Welsh JP, Knight SM (2003a) An economic analysis of the potential for precision farming in UK cereal production. Biosystems Engineering 84, 533-545.

Godwin RJ, Wood GA, Taylor JC, Knight SM, Welsh JP (2003b) Precision Farming of Cereal Crops: a Review of a Six Year experiment to development management guidelines. Biosystems Engineering 84, 375-391.

Hayman P (2001) Precision Agriculture in this land of droughts and flooding rains - a simulation study of nitrogen fertiliser for wheat on the Liverpool Plains, NSW. Paper presented to the Geospatial Information and Agriculture Conference. 17-19 July 2001, Sydney.

Hudson D, Hite D (2001) Adoption of Precision Agriculture Technology in Mississippi: Preliminary Results from a Producer Survey, Department of Agricultural Economics Research Report 2001001, Mississippi State University.

Kingwell R, Pannell D (2005) Economic trends and drivers affecting the Wheatbelt of Western Australia to 2030. Australian Journal of Agricultural Research 56, 553 - 561.

Lowenberg-DeBoer J. (2003) "Precision Agriculture or Convenience Agriculture" in Solutions for a Better Environment. Proceedings of the 11th Australian Agronomy Conference, 2-6 Feb, 2003, Geelong, Victoria. Published on CDROM ISBN 0-9750313-0-9. Australian Society of Agronomy.

McBratney A, Whelna B,Ancev T, Bouma J (2005) Future directions of precision agriculture. Precision Agriculture 6, 7-23.

Pringle MJ, McBratney AB, Whelan BM, Taylor JA (2003) A preliminary approach to assessing the opportunity for site-specific crop management in a field, using yield monitor data. Agricultural Systems 76, 273-292.

Price P (2004) Spreading the PA message. Ground Cover, Issue 51, August 2004. Grains Research and Development Corporation, Canberra.

Robertson MJ, Carberry PS, Brennan LE (2007) The economic benefits of precision agriculture: case studies from Australian grain farms. A report prepared for the Grains Research and Development Corporation. Available at www.grdc.com.au/

Robinson TP, Metternicht G (2005) Comparing the performance of techniques to improve the quality of yield maps. Agricultural Systems 85, 19-41.

Reid JB (2002) Yield response to nutrient supply across a wide range of conditions I. Model derivation. Field Crops Research 77, 161-171.

40 SAS Institute Inc. (2003) JMP User's Guide, Version 5, Cary, NC: SAS Institute Inc.

Whelan BM, McBratney AB, Minasny B (2001) Vesper - Spatial Prediction Software for Precision Agriculture. In G.Grenier \& S. Blackmore (eds) ECPA 2001, Proceedings of the 3rd European 
Conference on Precision Agriculture, Montpellier, France, agro-Montpellier, Montpellier,

France pp 139-144.

Whelan BM, McBratney AB (2003) "Definition and interpretation of potential management zones in Australia" in Solutions for a Better Environment. Proceedings of the 11th Australian Agronomy Conference, 2-6 Feb, 2003, Geelong, Victoria. Published on CDROM ISBN 0-9750313-0-9. Australian Society of Agronomy.

Wong MTF, Corner RJ, Cook SE (2001) A decision support system for mapping the site-specific potassium requirement of wheat in the field. Australian Journal of Experimental Agriculture 41, 644-661.

Figure 1
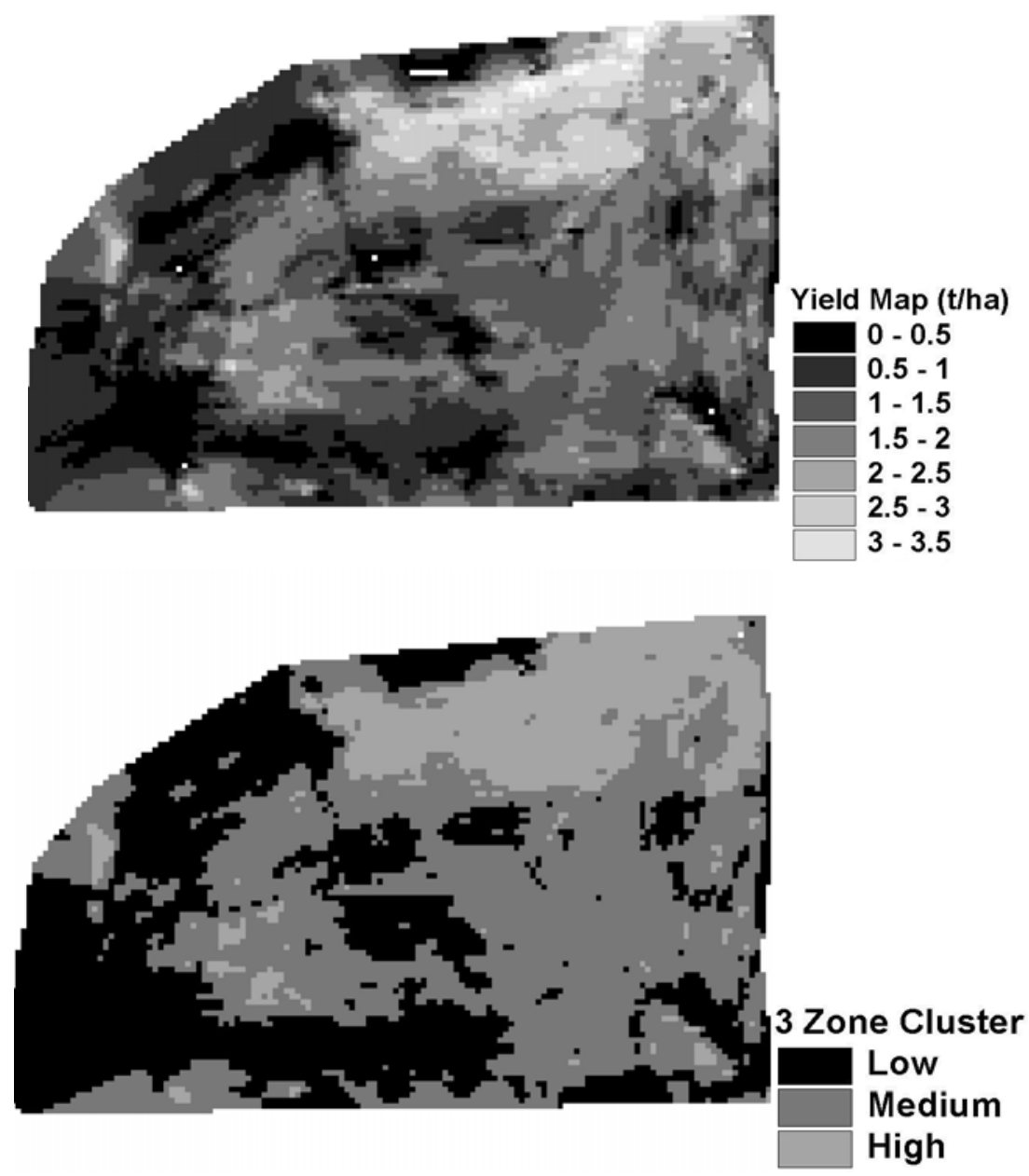
Figure 2

5

(a)

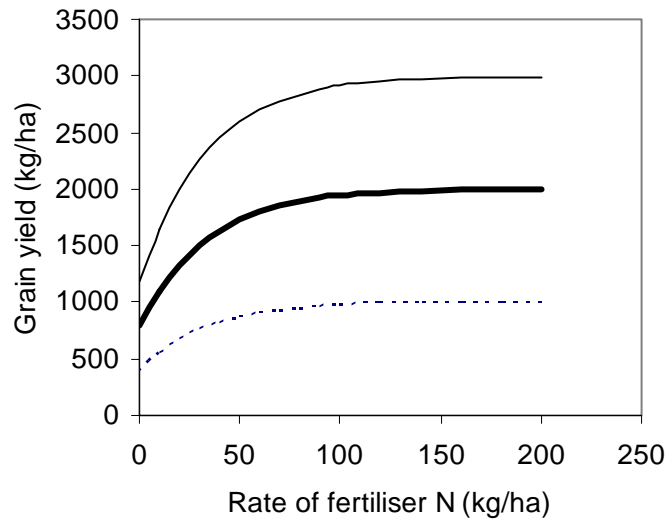

(c)

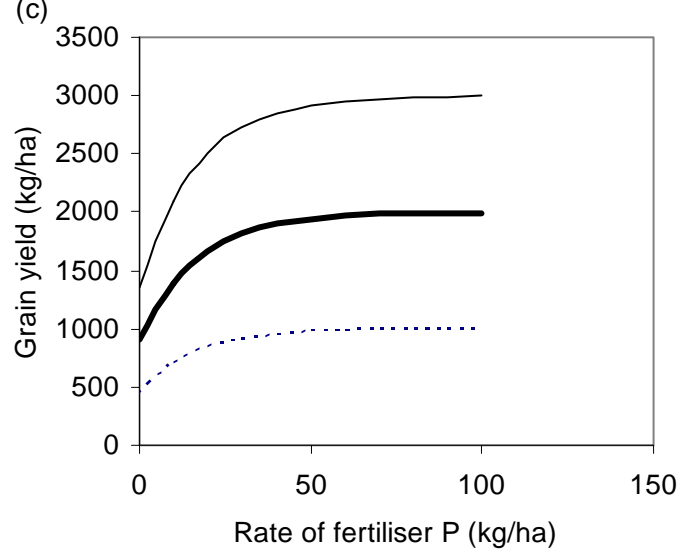

(b)

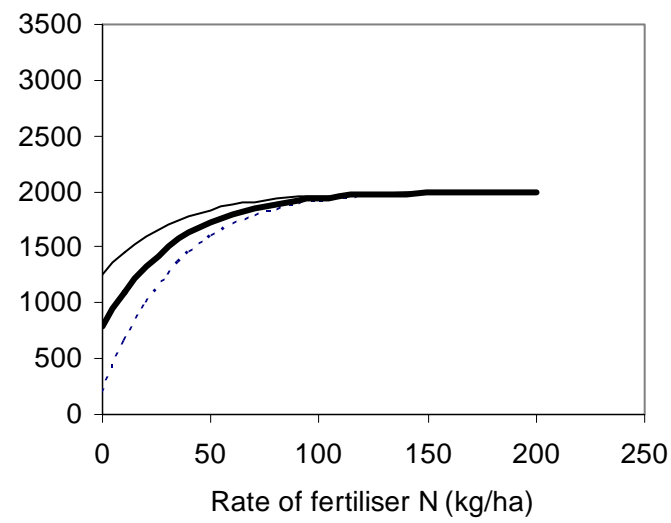

(d)

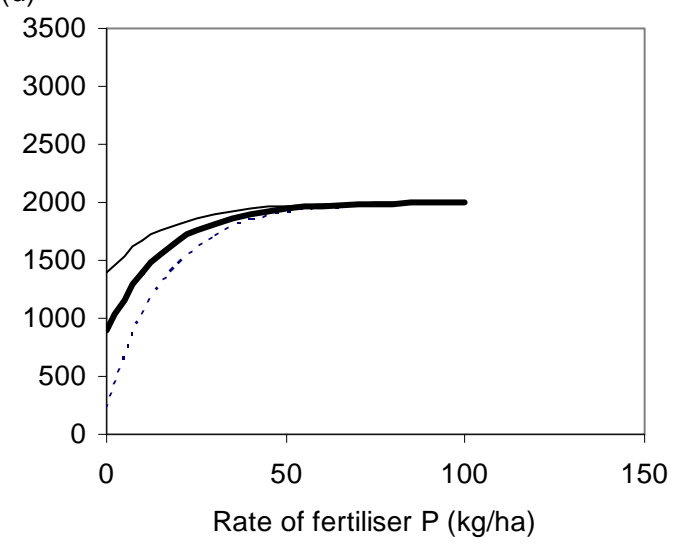


Figure 3

5

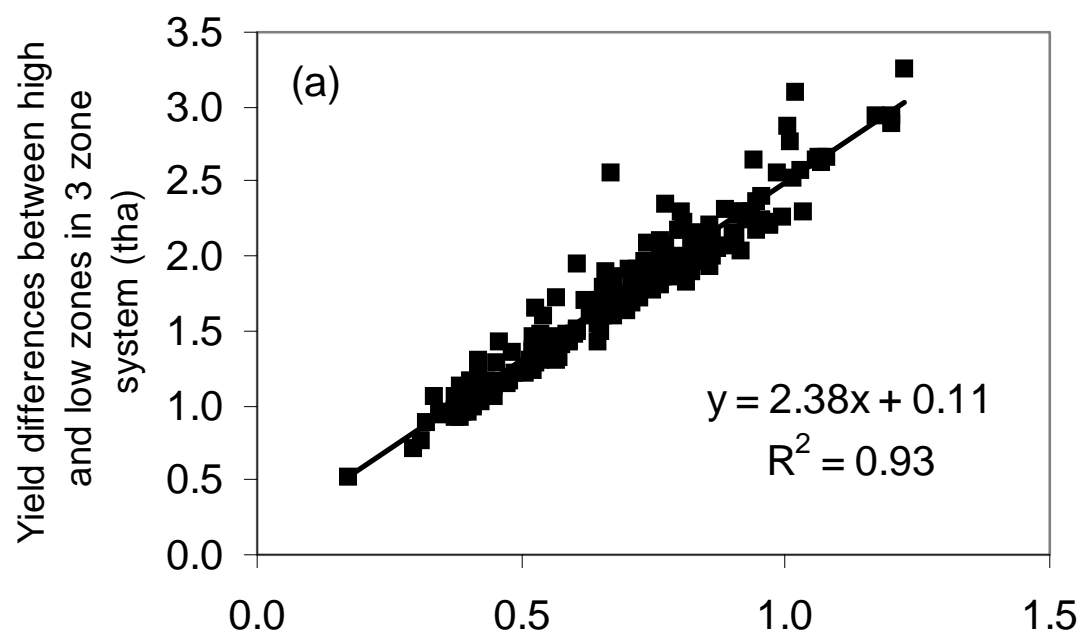

Field standard deviation (t/ha)

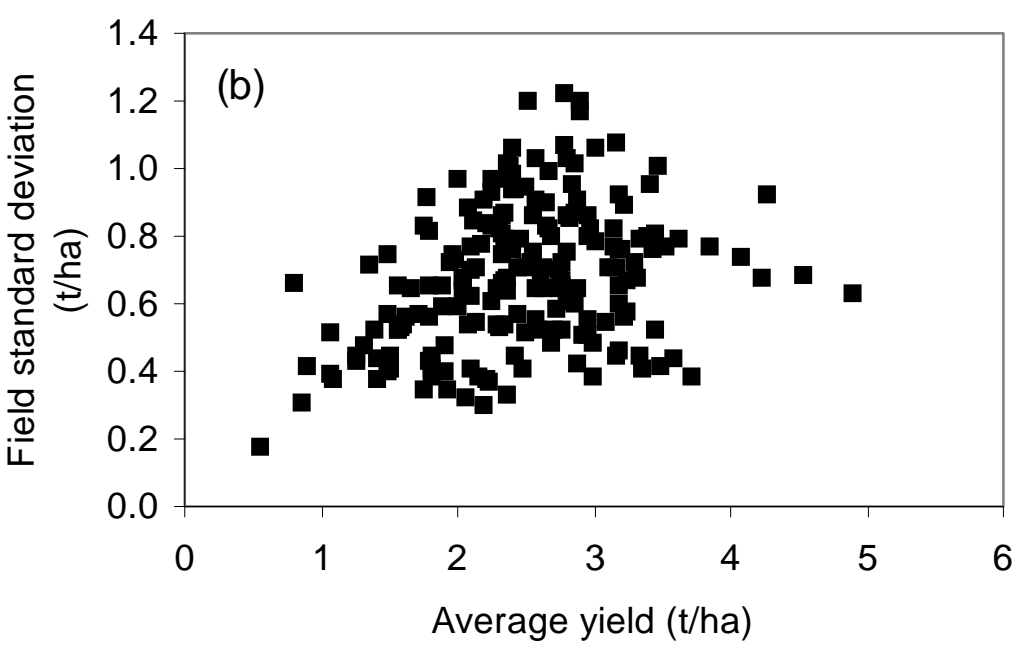




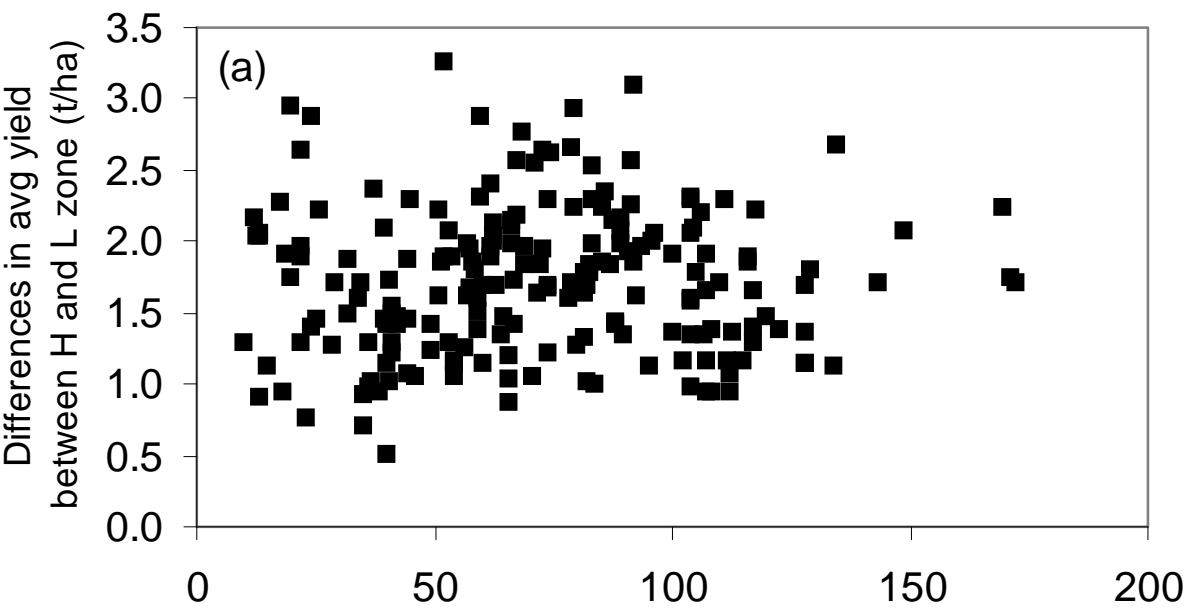

Field area (ha)

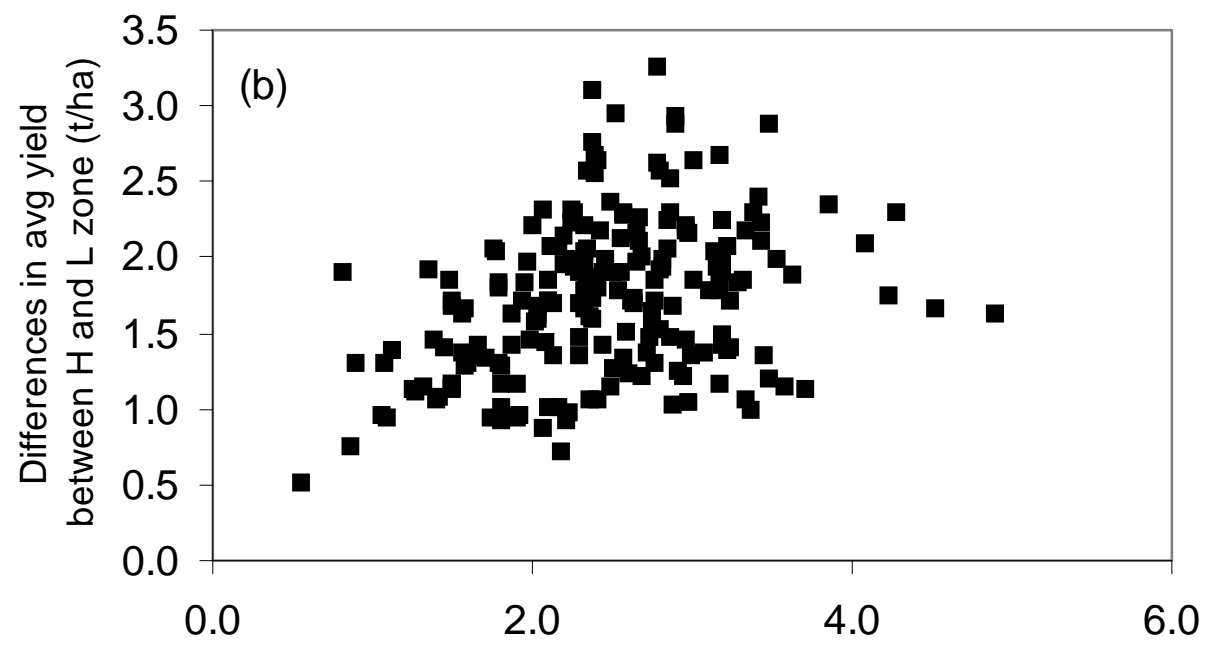

Field average yield (t/ha) 


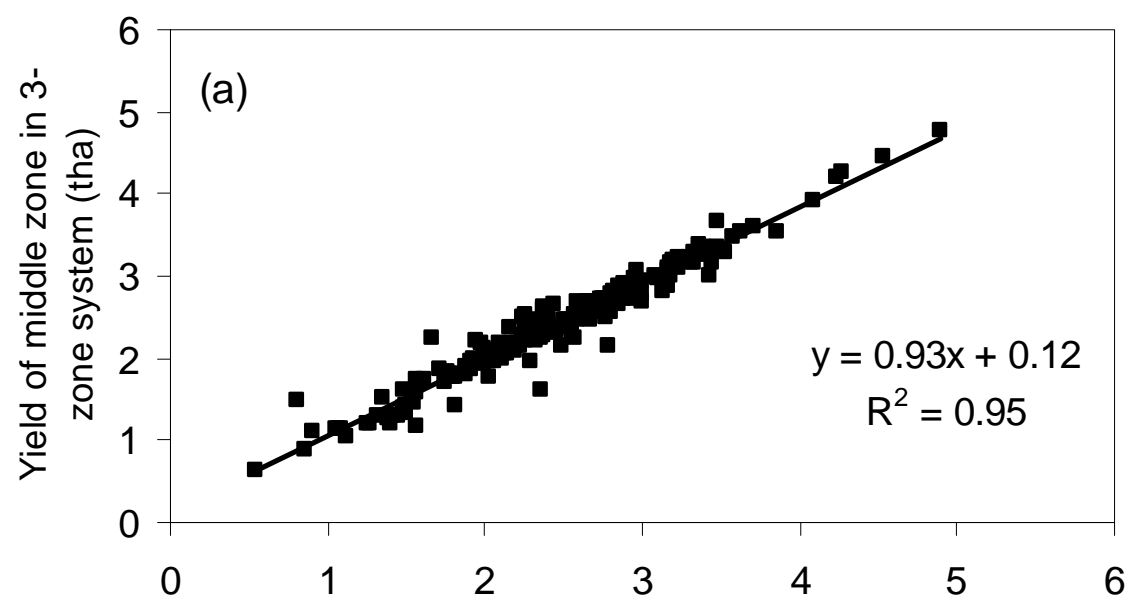

Field average yield (t/ha)
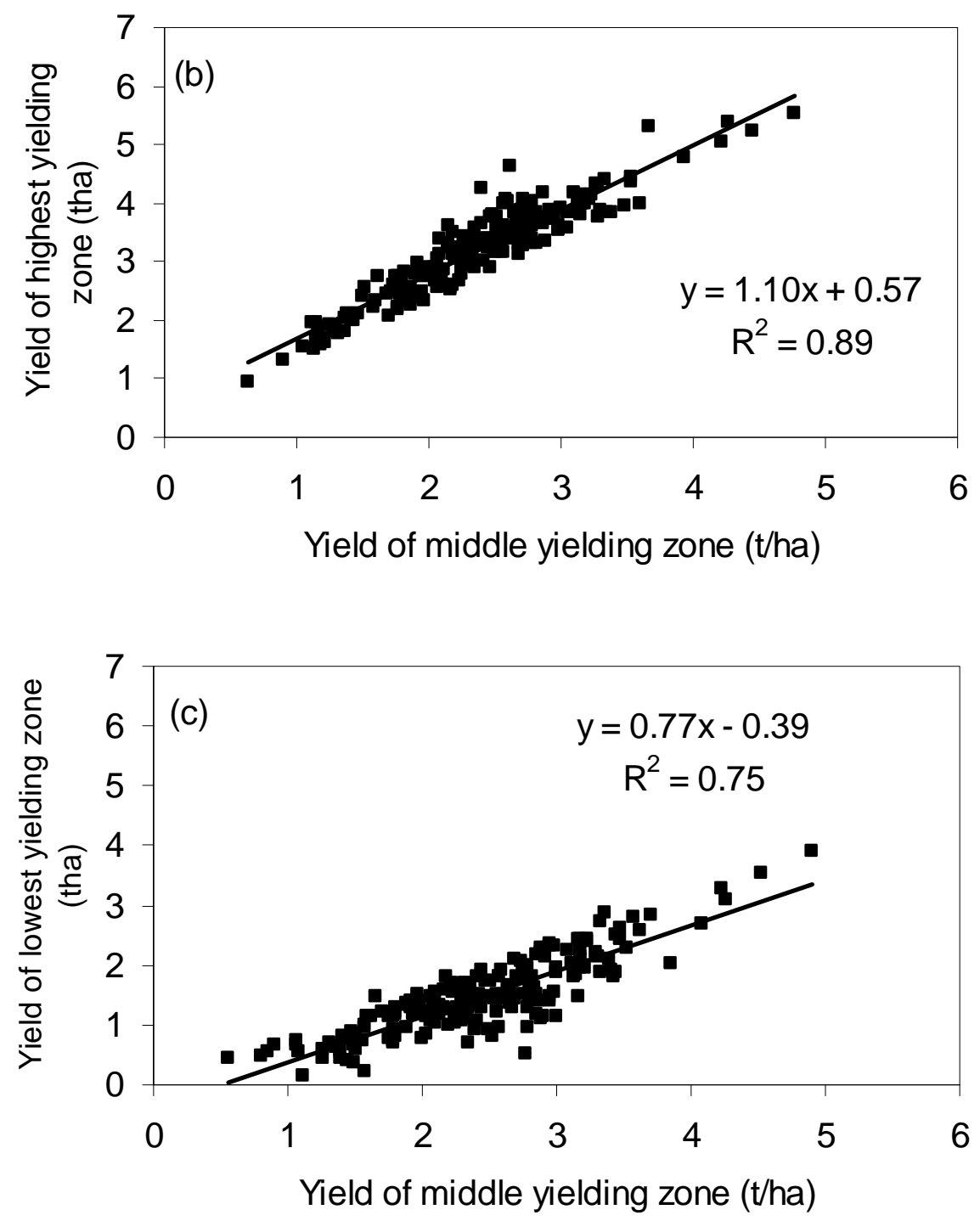